Nanopillar growth by focused helium ion-beam-induced deposition

This article has been downloaded from IOPscience. Please scroll down to see the full text article.

2010 Nanotechnology 21455302

(http://iopscience.iop.org/0957-4484/21/45/455302)

View the table of contents for this issue, or go to the journal homepage for more

Download details:

IP Address: 131.180.130.114

The article was downloaded on $27 / 12 / 2010$ at 15:18

Please note that terms and conditions apply. 


\title{
Nanopillar growth by focused helium ion-beam-induced deposition
}

\author{
Ping Chen ${ }^{1}$, Emile van Veldhoven ${ }^{2}$, Colin A Sanford ${ }^{3}$, \\ Huub W M Salemink ${ }^{1}$, Diederik J Maas ${ }^{2}$, Daryl A Smith ${ }^{4}$, \\ Philip D Rack ${ }^{4}$ and Paul F A Alkemade ${ }^{1}$ \\ ${ }^{1}$ Kavli Institute of Nanoscience, Delft University of Technology, Lorentzweg 1, \\ 2628 CJ Delft, The Netherlands \\ ${ }^{2}$ TNO Science and Industry, Stieltjesweg 1, 2628 CK Delft, The Netherlands \\ ${ }^{3}$ Carl Zeiss SMT, Inc., One Corporation Way, Peabody, MA 01960, USA \\ ${ }^{4}$ Department of Material Science and Engineering, University of Tennessee, Knoxville, \\ TN 37996-2200, USA \\ E-mail: p.f.a.alkemade@tudelft.nl
}

Received 2 August 2010, in final form 7 September 2010

Published 14 October 2010

Online at stacks.iop.org/Nano/21/455302

\begin{abstract}
A $25 \mathrm{keV}$ focused helium ion beam has been used to grow PtC nanopillars on a silicon substrate by beam-induced decomposition of a $\left(\mathrm{CH}_{3}\right)_{3} \mathrm{Pt}\left(\mathrm{C}_{\mathrm{P}} \mathrm{CH}_{3}\right)$ precursor gas. The ion beam diameter was about $1 \mathrm{~nm}$. The observed relatively high growth rates suggest that electronic excitation is the dominant mechanism in helium ion-beam-induced deposition. Pillars grown at low beam currents are narrow and have sharp tips. For a constant dose, the pillar height decreases with increasing current, pointing to depletion of precursor molecules at the beam impact site.

Furthermore, the diameter increases rapidly and the total pillar volume decreases slowly with increasing current.

Monte Carlo simulations have been performed with realistic values for the fundamental deposition processes. The simulation results are in good agreement with experimental observations. In particular, they reproduce the current dependences of the vertical and lateral growth rates and of the volumetric deposition efficiency. Furthermore, the simulations reveal that the vertical pillar growth is due to type- 1 secondary electrons and primary ions, while the lateral outgrowth is due to type-2 secondary electrons and scattered ions.
\end{abstract}

(Some figures in this article are in colour only in the electronic version)

\section{Introduction}

Ion-beam-induced deposition (IBID) is a direct writing technology in which precursor molecules adsorbed on a substrate surface are decomposed by an ion-beam-induced or ensuing secondary-electron-induced reaction, resulting in localized material deposition. Owing to its high flexibility regarding the shape and location of the deposits, IBID is becoming increasingly popular as a tool for prototyping threedimensional nanostructures $[1,2]$. So far, almost all IBID work is performed with $\mathrm{Ga}^{+}$focused ion beams (FIB), which have at best a probe size of $5 \mathrm{~nm}$ [3]. Only a few studies deal with broad $(\sim \mathrm{mm})$ noble-gas ion beams, like $\mathrm{He}^{+}, \mathrm{Ne}^{+}$and $\mathrm{Xe}^{+}[4,5]$. Despite the small probe size, structures grown with a stationary FIB-i.e. pillars-usually have a diameter of more than $100 \mathrm{~nm}$ [1, 6-8]. In addition, Ga-IBID pillars have rough sidewalls and relatively blunt tops [8]. The increased pillar width and surface roughness are not well understood. Pillars grown by electron-beam-induced deposition (EBID) are usually narrower and less pure [9].

Recently, helium ion microscopy (HIM) became commercially available [10] with a probe size much smaller than that of the best gallium beams [3]. Compared to scanning electron microscopy, HIM has the advantage of a smaller interaction volume in the substrate and a predominance of type1 secondary electron emission $\left(\mathrm{SE}_{1}\right)$ [10-15]. A helium ion microscope can also be used for nanofabrication. Sidorkin et al [16] and Winston et al [17] demonstrated the high-resolution manufacturing capabilities of $\mathrm{He}^{+}$beam lithography. Bell et al used an HIM to cut narrow graphene stripes [18]. Sanford et al 
[19] and Maas et al [20] showed that the introduction of a Ptcontaining precursor gas into the HIM results in the formation of a deposit at the area exposed to the $\mathrm{He}^{+}$beam. Furthermore, the deposition yield-i.e. the volume deposited per incident ion-for He-IBID is similar to that for Ga-IBID. However, the Pt content is lower [19], more like deposits made by EBID [9].

Material growth by IBID is intimately linked to the trajectories and the energy losses of the ions in the growing material. In the model of Dubner et al [4], the nuclear energy transfers to the atoms at or just below the surface constitute the mechanism of IBID. Another model relates IBID to precursor decomposition induced by electronic interactions with primary or backscattered ions and emitted secondary electrons [21].

This paper reports the first successful growth of narrow pillars with a stationary, nanometre-size $\mathrm{He}^{+}$beam. The experimental data are substantiated by extensive Monte Carlo simulations of the growth, using the recently developed 'EnvisION' Monte Carlo ion-beam-induced deposition code [22-27]. The main differences between He-IBID and Ga-IBID pillar growth will be discussed, as well as details of the mechanisms of IBID growth. This work demonstrates both the prospects of direct nanofabrication with focused helium ion beams and the feasibility of predicting growth characteristics by simulation.

\section{Experimental set-up}

The experiments were performed in a Carl Zeiss Orion ${ }^{\mathrm{TM}}$ Plus scanning helium ion microscope (HIM), equipped with an omniGIS unit from Omniprobe. This unit provides a mixture of gases via a nozzle with a $500 \mu \mathrm{m}$ wide opening, positioned at a distance of $\sim 500 \mu \mathrm{m}$ above the specimen surface. The angle between the nozzle and the surface normal is $25^{\circ}$. $\left(\mathrm{CH}_{3}\right)_{3} \mathrm{Pt}\left(\mathrm{C}_{\mathrm{P}} \mathrm{CH}_{3}\right)$ was used as the precursor. Its reservoir was heated to $30^{\circ} \mathrm{C}$ during deposition. A carrier gas of $\mathrm{N}_{2}$ was mixed with the Pt precursor gas in a ratio of about 10:1. The flow of the gas to the substrate was continuous. The background pressure in the chamber was $6.3 \times 10^{-7} \mathrm{mbar}$ and the pressure during deposition was $4.5 \times 10^{-6}$ mbar. A $25 \mathrm{keV} \mathrm{He}{ }^{+}$beam at normal incidence was used. The substrate material was Si with a native oxide. Deposition was achieved with a stationary $\mathrm{He}^{+}$beam. The exposure-time dependence was measured for a primary beam current of $0.6 \mathrm{pA}$ and the current dependence between 0.6 and $5.0 \mathrm{pA}$ for a total dose $Q$ of $6.0 \mathrm{pC}$ per deposit. The current was regulated via the helium gas pressure in the source. Typical variation in pillar widths and heights between different days is 5 and 10\%. The estimated probe size was $1 \mathrm{~nm}$ full width at half-maximum. In each run, four deposits were made sequentially under the same conditions. The deposits were imaged by subsequent HIM with a $0.5 \mathrm{pA}$ beam current and at $0^{\circ}$ and $30^{\circ}$ sample tilt. To check possible beam erosion and other beam-induced effects during imaging consecutive images were taken.

\section{Monte Carlo simulations}

The He-IBID growth of the pillars was simulated using the recently developed 'EnvisION' Monte Carlo ion-beaminduced deposition code [22]. The simulation was based on

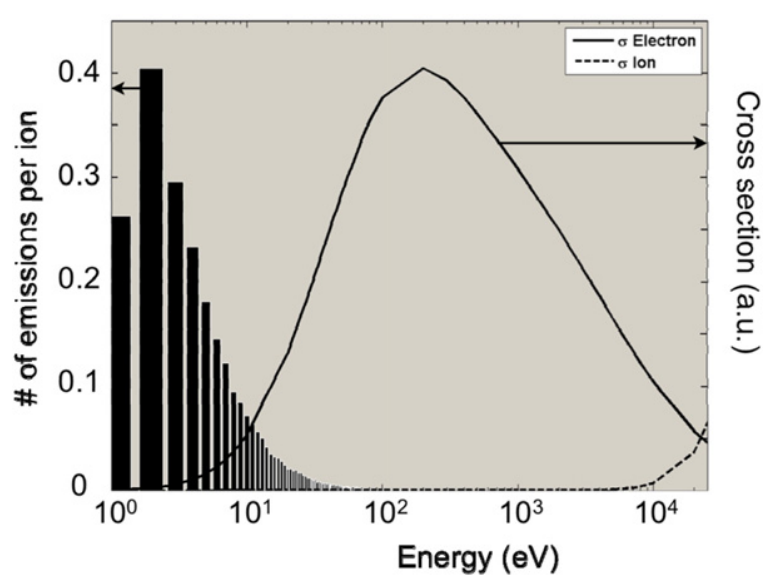

Figure 1. Electron-and ion-induced dissociation cross sections of $\left(\mathrm{CH}_{3}\right)_{3} \mathrm{Pt}\left(\mathrm{CPCH}_{3}\right)$. The electron data are a fit to the data in [30]. The ion data are derived from the latter by scaling via the stopping power at the same velocity. The histogram is the simulated secondary electron energy distribution, adjusted to a secondary electron coefficient of 2.9 for a flat $\mathrm{Pt}_{20} \mathrm{C}_{80}$ substrate of [29].

an electron-beam-induced simulation [23-26] and the 'IoniSE' ion-solid/secondary electron beam Monte Carlo routine [27]. The input parameters used are: beam energy $25 \mathrm{keV}$; ion currents of $0.6,1,3,5$ and $9 \mathrm{pA}$; a Gaussian beam shape with a full width at half-maximum of $1 \mathrm{~nm}$; a homogeneous composition of $20 \% \mathrm{Pt}$ and $80 \% \mathrm{C}$ [19] with a density of $4.5 \mathrm{~g} \mathrm{~cm}^{-3}$ [28] and a total ion-induced secondary electron yield of 2.9 electrons/ion for a flat $\mathrm{Pt}_{20} \mathrm{C}_{80}$ substrate, equal to the yields for both pure $\mathrm{C}$ and pure $\mathrm{Pt}$ [29]. The corresponding molecular density is $11 \mathrm{PtC}_{4} \mathrm{~nm}^{-3}$. From the throughput of the gas $\left(\sim 10^{-3} \mathrm{mbarl} \mathrm{s}^{-1}\right)$ and the distance of $500 \mu \mathrm{m}$ of the nozzle to the beam spot we estimated a localized $\left(\mathrm{CH}_{3}\right)_{3} \mathrm{Pt}\left(\mathrm{C}_{\mathrm{P}} \mathrm{CH}_{3}\right)$ pressure of $1.3 \times 10^{-2} \mathrm{mbar}$. The assumed sticking coefficient is 0.1 [9]. The electron-beaminduced dissociation cross section as a function of energy is from recent measurements by Van Dorp et al [30] for the $\left(\mathrm{CH}_{3}\right)_{3} \mathrm{Pt}\left(\mathrm{C}_{\mathrm{P}} \mathrm{CH}_{3}\right)$ precursor on amorphous carbon, see figure 1 . The ion beam cross section was generated by scaling the electron beam cross section via the ratio of the electronic stopping power of $\mathrm{Pt}_{20} \mathrm{C}_{80}$ for helium ions and for electrons at equal velocity $[27,31,32]$.

Figure 1 also shows a histogram plot of the secondary electron energy spectrum generated from 10000 helium ions incident on a flat $\mathrm{Pt}_{20} \mathrm{C}_{80}$ substrate. The corresponding simulated backscattered ion yield is $5.1 \%$, the peak implant range $\left(R_{\mathrm{p}}\right)$ is $216 \mathrm{~nm}$ and the $90 \%$ ion range $\left(R_{90}\right)$ is $255 \mathrm{~nm}$. The range values are in good agreement with the values of $R_{\mathrm{p}}(187 \mathrm{~nm})$ and $R_{90}(220 \mathrm{~nm})$ in [27]. Furthermore, the simulated lateral straggle peak $\left(S_{\mathrm{p}}\right)$ is $86 \mathrm{~nm}$ and the $90 \%$ lateral straggle distance $\left(S_{90}\right)$ is $181 \mathrm{~nm}$. The $\mathrm{SE}_{1}$ and $\mathrm{SE}_{2}$ electrons are differentiated by the Monte Carlo scattering step: the $\mathrm{SE}_{1}$ electrons are created during the first five ion scattering steps and $\mathrm{SE}_{2}$ electrons beyond the fifth step. For a flat $\mathrm{PtC}$ substrate, the average depth and radial distance of the fifth scattering event are 43 and $6.1 \mathrm{~nm}$, respectively, and the average depth and radial distance of $\mathrm{SE}_{1}$ electrons are 7.7 and $2.1 \mathrm{~nm}$, respectively. 


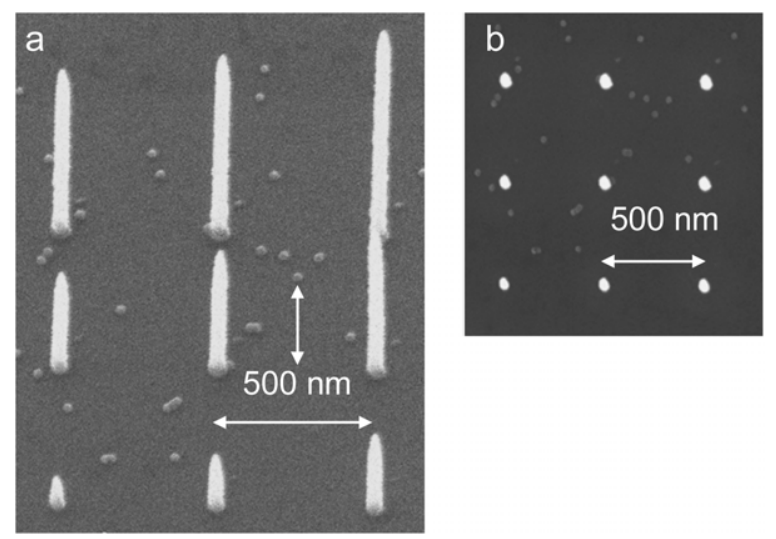

Figure 2. Pillars grown from $\left(\mathrm{CH}_{3}\right)_{3} \mathrm{Pt}\left(\mathrm{CPCH}_{3}\right)$ decomposition by a $1 \mathrm{~nm} \mathrm{He}{ }^{+}$beam at $0.6 \mathrm{pA}$ and $25 \mathrm{keV}$. Exposure dose ranged from 0.6 (lower left) to 5.4 (upper right) pC. (a) $30^{\circ}$ tilted view and (b) top view.

\section{Results}

The HIM images of the deposits for different exposure times are shown in figure 2 . The deposits are pillar-shaped structures. Their diameter and height are plotted in figure 3 as a function of the exposure time. The height increases proportionally with time and, apart from the initial growth, the pillar width is constant

Figure 4 shows a compilation of deposits, grown with different currents but with the same ion dose. All deposits are cones at high currents and pillars, i.e. cylinders with conical tops, at lower currents. Figure 4(b) is a magnified HIM image of one of the pillars deposited at $0.8 \mathrm{pA}$. The bending of the top is caused by ion impacts during imaging at high resolution. The apex has a radius of curvature of $9 \pm 2 \mathrm{~nm}$ and the pillar has a width at half-maximum of $36 \pm 2 \mathrm{~nm}$. Furthermore, the sidewalls of all pillars are smooth. Note that the conical top of the pillars are typically about $100-150 \mathrm{~nm}$ long. The pillars grown at the higher currents are shorter and broader. The ellipse in figure 4(b) is the estimated location of the pillar bottom.

Figure 5(a) shows the measured height $H$ and 5(b) the vertical growth rate $v_{\mathrm{V}}(=H i / Q)$ of the deposits as a function of the primary beam current $i$. The current variation was achieved via variation of the helium gas pressure, which should not affect the beam diameter [33].

Figure 5(c) shows the full width at half-maximum and figure 5(d) the deposited volume per incident ion. Because of the unfavourable viewing direction, we estimate that the error in the pillar volume ranges from $5 \%$ for the tall and narrow pillars to $10 \%$ for the short, conical structures. The general conclusion of figure 5 is that, with increasing beam current, the deposits become shorter and broader while their total volume decreases slightly.

Figure 6 shows the length $L_{90}$ of the conical top versus the pillar diameter; $L_{90}$ is defined as the distance below the apex where the pillar diameter is $90 \%$ of its final, saturated diameter.

Figure 7 shows cross sections of four simulated pillars grown to a common height of $200 \mathrm{~nm}$ (requiring different

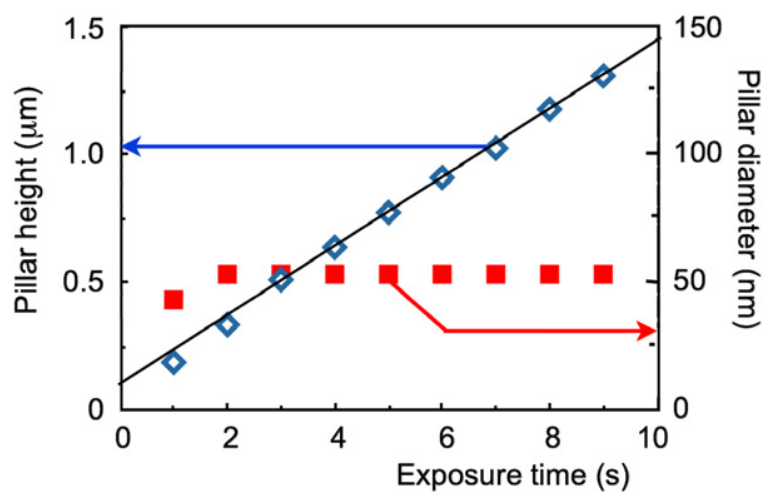

Figure 3. Pillar height and diameter versus exposure time (from data of figure 2). The line is a linear fit to the height data above $2 \mathrm{~s}$.

doses) for the respective currents from 1 to $9 \mathrm{pA}$. Figure 8 shows the simulated deposition events as a function of ion dose. All maximal doses shown correspond to a pillar height of $200 \mathrm{~nm}$. Figure 5 also shows the simulated height, vertical growth rate, width and volumetric deposition efficiency as a function of current. To compare the simulation results for the $200 \mathrm{~nm}$ pillars of figures 7 and 8 to the experimental $6 \mathrm{pC}$ growths in figure 5, we have normalized the simulated results. Note that $6.0 \mathrm{pC}$ corresponds to $3.73 \times$ $10^{7}$ ions. The simulated height in figure 5(a) is a simple linear extrapolation, based on the observed (figure 3) and simulated (not shown) constant vertical growth rate. The simulated pillar diameter shown in figure 5(c) is determined at $15 \mathrm{~nm}$ from its base, which we assume to approximate the steady-state nanopillar width, thus also the diameter at $6.0 \mathrm{pC}$ dose. Finally, the simulated volumetric deposition efficiency in figure $5(\mathrm{~d})$ is the weighted average of the volumetric deposition efficiency for the simulated $200 \mathrm{~nm}$ pillar and the steady-state volumetric deposition efficiency for the remaining dose up to $3.73 \times 10^{7}$ ions or $6.0 \mathrm{pC}$. The comparison between the experimental and the simulated pillars reveals good agreement. The simulations reproduce the trends: the vertical growth rate decreases, the pillar broadens and the volumetric deposition efficiency decreases as the beam current increases. The normalized simulated pillars are about $50 \%$ taller and $10 \%$ narrower, while their deposition efficiencies are about $25 \%$ higher and vary more strongly with ion current. The differences between the experimental and simulation results are most likely due to the uncertainties in a number of input parameters. An examination of the sources of uncertainty is given in section 5 .

\section{Discussion}

The experiments show that smooth and narrow nanopillars can be grown by helium ion-beam-induced decomposition of adsorbed $\left(\mathrm{CH}_{3}\right)_{3} \mathrm{Pt}\left(\mathrm{C}_{\mathrm{P}} \mathrm{CH}_{3}\right)$. Pillars grow in two stages: first as a cone and subsequently as a cone with a cylindrical base. For the conditions investigated, the pillar's vertical growth rate is constant in time (figure 3). The vertical growth rate increases with increasing beam current, but it levels off at the higher currents (figure 5(b)). This behaviour is unmistakably 

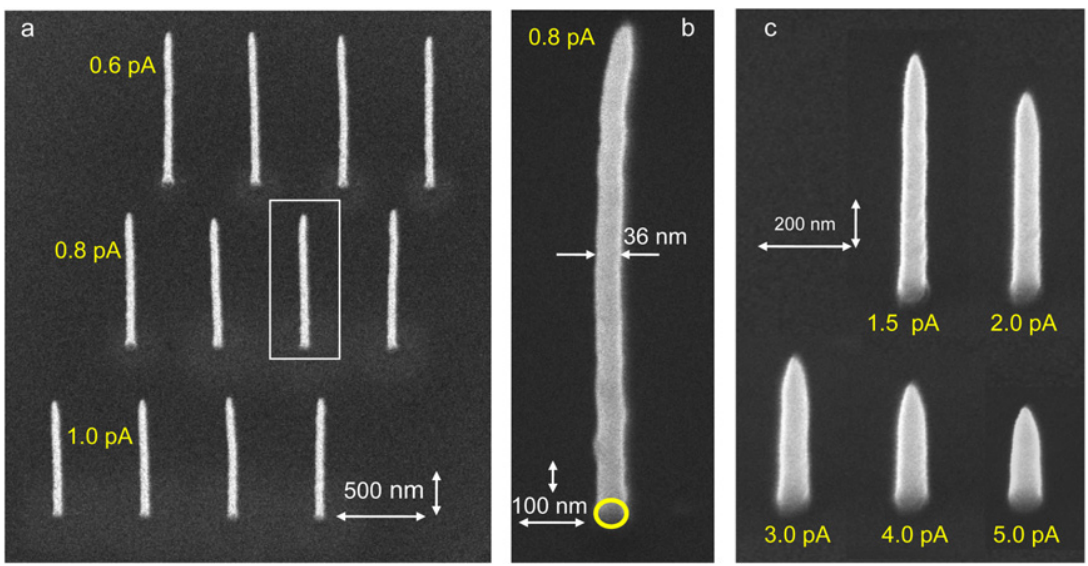

Figure 4. Pillars grown at $6.0 \mathrm{pC}$ and $25 \mathrm{keV} \mathrm{He}^{+}$viewed at $30^{\circ}$ sample tilt. (a) At low currents; (b) blow up of the enclosed pillar, the yellow ellipse is the estimated pillar bottom and (c) at high currents.

characteristic for the transition from an ion-limited growth regime to a precursor-limited regime [9]. The vertical growth rate $v_{\mathrm{V}}$ can be described by $[9,34,35]$

$$
v_{\mathrm{V}}(i)=\frac{v_{\infty} i}{i_{\mathrm{t}}+i}
$$

where $i_{\mathrm{t}}$ is the transition current between the two regimes and $v_{\infty}$ is the vertical growth rate in the saturated precursor-limited regime. The full curve of figure 5(b) is a fit to all experimental data with $v_{\infty}=400 \pm 20 \mathrm{~nm} \mathrm{~s}^{-1}$ and $i_{\mathrm{t}}=0.80 \pm 0.05 \mathrm{pA}$. The pillar top is supplied with precursor molecules via direct adsorption from the gas phase and via surface diffusion along the pillar sidewall. The levelling of the vertical growth rate clearly indicates that the supply of precursor molecules to the top of the growing pillar does not keep up with the ion flux at the higher beam currents. Nevertheless, the slow decline in figure 5(d) suggests that the supply of precursor molecules to the entire beam interaction region-i.e. the apex plus the surface of the cone-is almost sufficient to maintain a constant, current-independent volumetric deposition efficiency.

Examination of figure 7 and the temporal evolutions of the deposited species versus dose (or number of ions) in figure 8 reveals interesting details regarding the simulated growth of the nanopillars. The first observation is that the simulated sizes and shapes of the conical tops in figure 7 correspond well with the experimental ones in figure 4. See also figure 6. Furthermore, the cessation of lateral growth at 100-150 nm below the apex, which defines the length of the cone, is appreciably less than the implant range $R_{90}$ of $25 \mathrm{keV} \mathrm{He}$ ions in bulk $\mathrm{Pt}_{20} \mathrm{C}_{80}$ $(\sim 255 \mathrm{~nm})$. The third observation is the effect the current has on the number of molecules deposited by primary ions and $\mathrm{SE}_{\mathrm{I}}$ electrons (figure 7). As described previously [22], the vertical growth is dominated by primary ions (PI) and $\mathrm{SE}_{\mathrm{I}}$ electrons, as these species are responsible for the decomposition of the precursor molecules near the apex of the nanopillar surface. As shown in figure 8, deposition efficiencies for both the PI and $\mathrm{SE}_{\mathrm{I}}$ decrease with increasing current. If one assumes that the flux of precursor molecules is isotropic and the growth regime is precursor-limited, then it logically follows that the deposition efficiency will vary proportionally to the ratio of the flux of precursor molecules to the flux of ions. Thus, the decreasing PI and $\mathrm{SE}_{\mathrm{I}}$ deposition efficiencies and decreasing pillar height make intuitive sense: they can be understood by the decreasing precursor coverage in the beam interaction region. Figure 9 shows the simulated surface coverage as a function of the nanopillar height below the apex, which illustrates the precursor consumption in the beam interaction region. As hypothesized above, the surface coverage at the nanopillar apex does not keep up with the ion flux at all, especially at the higher currents. In particular, the relative surface coverage at the apex decreases from $18 \%$ at $1 \mathrm{pA}$ to $5 \%$ at $9 \mathrm{pA}$. The surface coverage over the entire beam interaction region is also reduced, but it is still much higher than at the apex. For instance, integrated from 50 to $200 \mathrm{~nm}$, the relative coverage varies from $86 \%$ for the $1 \mathrm{pA}$ to $68 \%$ for the $9 \mathrm{pA}$ simulations. The drop of about $25 \%$ in the simulated coverage in the entire beam interaction region explains the moderate decline of the volumetric deposition efficiency in figure 5(d).

To understand the nanopillar broadening with increasing current, it is instructive to realize that $\mathrm{SE}_{1}$ and $\mathrm{SE}_{2}$ electrons as well as forward scattered ions contribute to the pillar broadening. Interestingly, the increased current broadens the pillars, although it reduces-see figure 8-both the deposition efficiencies for $\mathrm{SE}_{1}$ and $\mathrm{SE}_{2}$ electrons due to a decreased surface coverage. However, the relative $\mathrm{SE}_{2}$ contribution increases and in steady state becomes much larger than the relative $\mathrm{SE}_{1}$ contribution. The broadening is basically a result of competing vertical and lateral growth. The time $t_{\mathrm{L}}$ available for lateral growth is inversely proportional to the vertical growth rate $\left(t_{\mathrm{L}} \sim R_{\mathrm{p}} / v_{\mathrm{V}}\right)$. The vertical growth rate saturates for the higher currents in our experiments. Though the lateral growth time is slightly shorter for the higher currents, the lateral growth rate is proportionally higher due to the higher intensity of $\mathrm{SE}_{2}$ electrons and forward scattered ions. Thus, higher currents imply faster lateral growth and an almost constant vertical growth. This effect explains the observed pillar broadening with increasing ion current. An analytical analysis of the interplay between vertical and lateral growth is given in [35].

The increase of the simulated cone lengths - the $L_{90}$ distances in figure 6 -is consistent with the experimental 


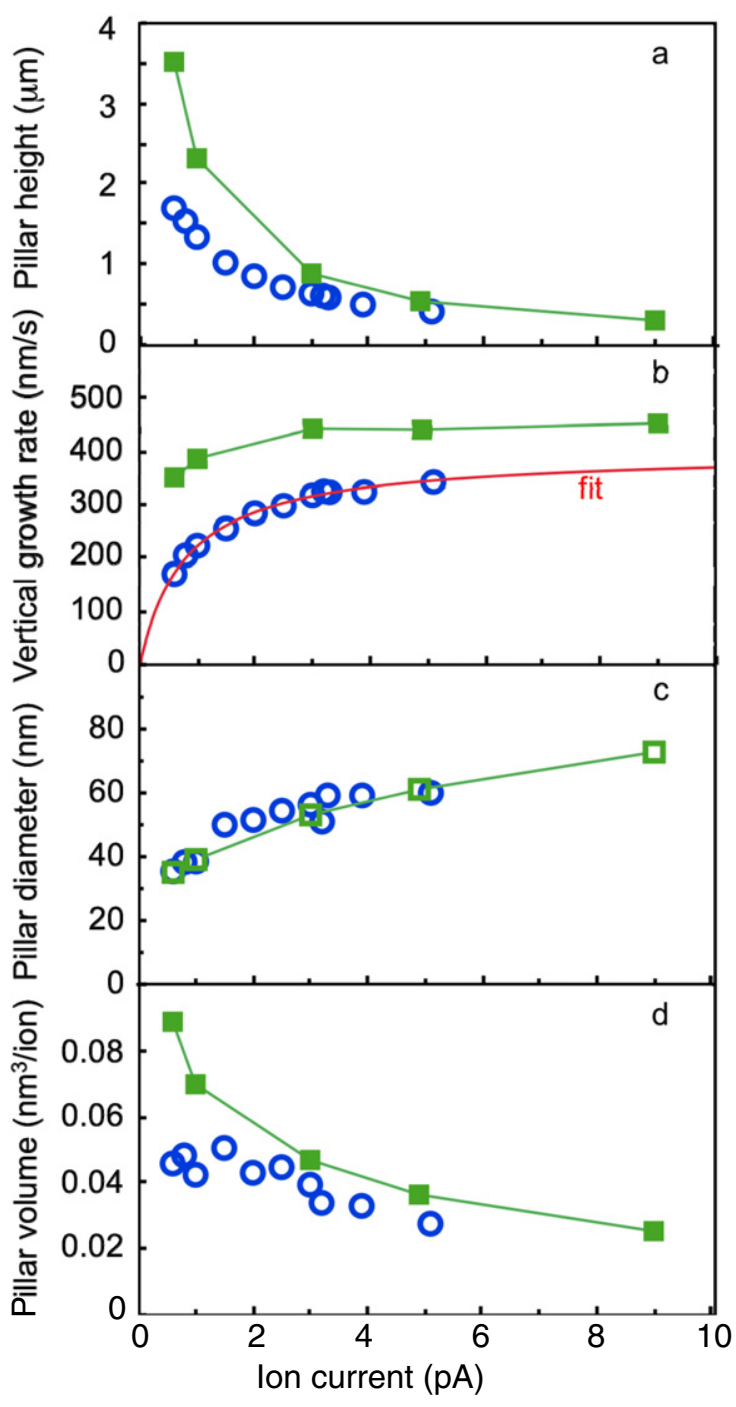

Figure 5. Growth characteristics versus beam current for a dose of $6.0 \mathrm{pC}$; open blue circles are experimental data; green squares are simulation data (line is only a guide to the eyes). (a) Pillar height; (b) vertical growth rate, red curve is a fit of equation (1); (c) pillar full width at half-maximum and (d) deposited volume per incident ion, i.e. the volumetric deposition efficiency.

data. As the nanopillar broadens with increasing current, the effective vertical interaction length of the nanopillar increases and is eventually expected to saturate at the bulk value of $\sim 255 \mathrm{~nm}$. The difference between the cone length $\left(L_{90}\right)$ and the bulk implant depth is, thus, due to the premature escape of almost all ions from the narrow pillars. Note that the lateral straggle in bulk $\mathrm{Pt}_{20} \mathrm{C}_{80}$ is still much larger $\left(S_{90}=181 \mathrm{~nm}\right)$ than the widest pillars ( $40 \mathrm{~nm}$ radius) observed in this study. To conclude, most of the incident ions scatter out of the nanopillar before they can traverse the full penetration distance.

Although good agreement between experiment and simulation has been obtained, uncertainties in parameters should be considered. First of all, the localized pressure for the simulations might differ from the actual one. Uncertainties in the specific partial pressure of the precursor and the sticking coefficient are likely the largest source of error. Logically, the vertical growth rate in the precursor-limited regime will scale

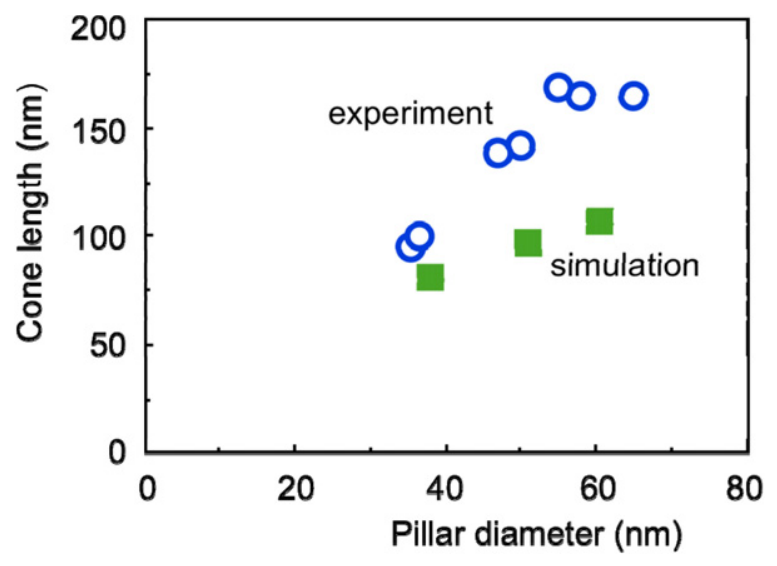

Figure 6. Cone length $L_{90}$ versus pillar diameter.

with the localized pressure and with the sticking probability; in fact, the growth depends on their product. Of course, a change in the vertical growth rate will also affect the pillar width. In addition, we have made assumptions on the composition, microstructure and density of the nanopillars. Surface diffusion of precursors could also be operative which would increase the coverage in the beam interaction region [24]. Furthermore, we assume that increasing the beam current by increasing the helium pressure did not broaden the beam. However, this conjecture was not checked experimentally. A broader beam would affect both the pillar width and the deposition efficiency. We have used the electron beam total dissociation cross-section data from [30] for the electron- and ion-beaminduced deposition cross sections. While dissociation is a necessary step in the deposition, it is likely not a simple first-order process and the total ion- and electron-beaminduced deposition cross sections might differ. Finally, all simulations were performed at room temperature. Thus, possible beam heating effects on precursor decomposition or adsorption were ignored. In a future study we will investigate the effects of localized pressure, heating, surface diffusion, precursor residence time, sticking probability, beam diameter, ion and electron dissociation cross sections as well as a more exhaustive investigation of the interactions between these parameters.

The measured deposition efficiency of $0.04 \mathrm{~nm}^{3} /$ ion is comparable to the experimental values between 0.04 and $0.09 \mathrm{~nm}^{3} /$ ion found by Sanford et al [19] for the growth of $\mathrm{PtC}$ with a similar instrument and for similar experimental conditions. However, in [19] a scanning beam was used and boxes of $\mathrm{Pt}$ were deposited of sizes larger than $500 \mathrm{~nm}$. The deposition efficiency for Pt-pillar growth via Ga-IBID is $0.045 \mathrm{~nm}^{3} /$ ion at $30 \mathrm{keV}$ [8]. Assuming a density of $4.5 \mathrm{~g} \mathrm{~cm}^{-3}$ [28] and a $\mathrm{C}$ to $\mathrm{Pt}$ ratio of 4:1 [19], a deposition efficiency of $0.04 \mathrm{~nm}^{3}$ /ion corresponds to a deposition yield of 2.2 atoms/ion. In EBID, the deposition yield for the same precursor is much lower, under favourable conditions still below $0.001 \mathrm{~nm}^{3} /$ electron [36]. Although ion beam deposition by $\mathrm{He}^{+}$and by $\mathrm{Ga}^{+}$ions have similar deposition yields [37], their nuclear stopping powers-i.e. the average energy loss per unit of path length via nuclear or atomic collisions-differ 


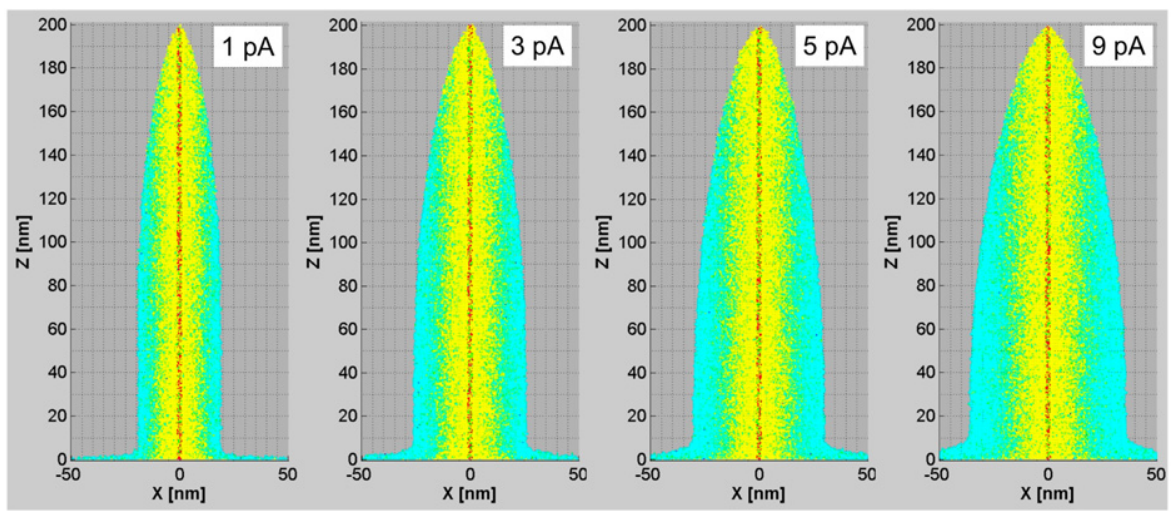

Figure 7. Cross sections of the simulated pillars for various currents. The colour or shade codes the type of particle that caused deposition. From centre to rim: red (black): primary ions; yellow (white): $\mathrm{SE}_{1}$ electrons; green (dark grey): forward scattered ions; cyan (light grey): $\mathrm{SE}_{2}$ electrons. The few backscattered ions are not visible.

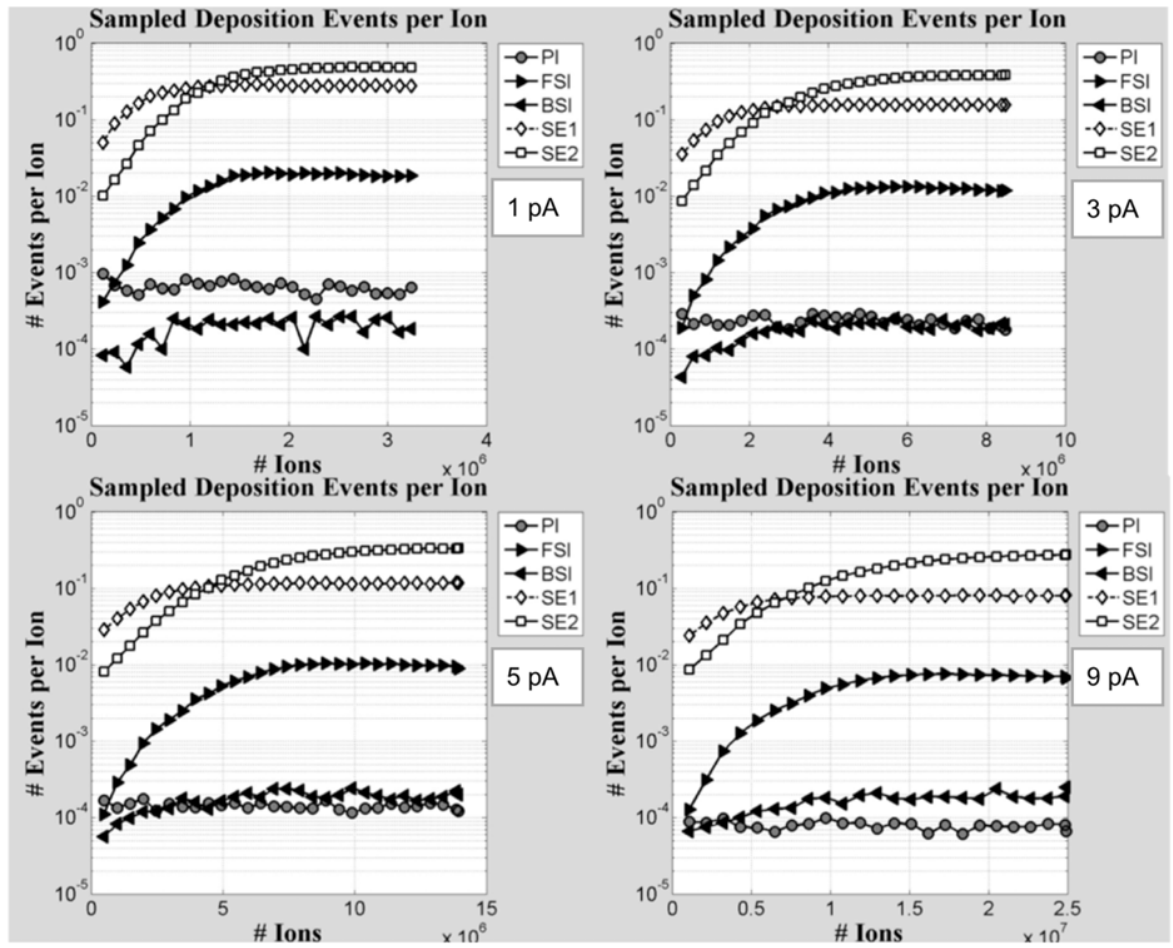

Figure 8. Calculated contribution of the various deposition events as a function of ion dose (or time). Each deposition event corresponds to one precursor molecule decomposition, whereby one $\mathrm{Pt}$ atom and four $\mathrm{C}$ atoms are being deposited onto the growing pillar surface. At a pillar height of $200 \mathrm{~nm}$, the deposition events per ion reach their steady-state values.

by almost two orders of magnitude. Because of this large discrepancy we conclude that the atomic-collision model by Dubner [4] is not applicable for He-IBID and we attribute the mechanism of He-IBID to molecular decomposition induced by electronic excitations [21]. However, the electronicexcitation mechanism cannot explain the large difference between He-IBID and EBID.

The He-IBID pillars are up to four times narrower and have a sharper apex than Ga-IBID pillars. In fact, the width and apex are as good as for the best PtC tips grown by EBID [38]. We tentatively attribute the differences in top shape and size to the differences in penetration depth, lateral straggle and the occurrence of non-negligible milling during Ga-IBID. Finally, the He-IBID pillars are smooth, while the Ga-IBID pillars have rough sidewalls.

\section{Conclusions}

Nanopillars with a diameter of less than $40 \mathrm{~nm}$ and an apex radius of $9 \mathrm{~nm}$ can be grown by focused $\mathrm{He}$ ion-beaminduced deposition (He-IBID). Pillars grown at higher currents are shorter and broader, but their volumes are only slightly less than for pillars grown at lower currents. The shape change is a consequence of a transition in the vertical growth from the ion-limited regime to the precursor-limited regime. 


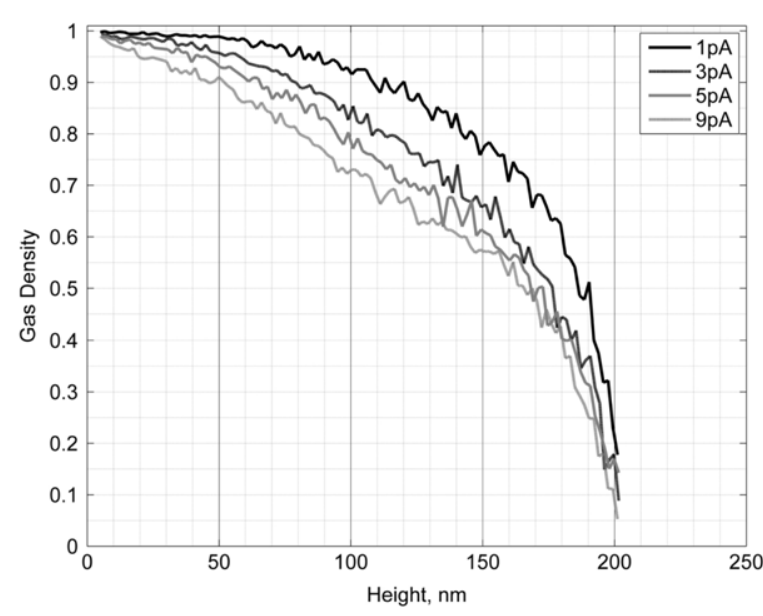

Figure 9. Relative surface coverage of precursor molecules on the pillar for various currents. All pillars are $200 \mathrm{~nm}$ high.

Deposition yields are as high as for Ga-IBID, and much higher than for electron-beam-induced deposition (EBID). The fact that electronic stopping power dominates the energy loss for $25 \mathrm{keV}$ (and lower) $\mathrm{He}$ ions suggests that electronic excitation is the mechanism of He-IBID. Quantitative Monte Carlo simulations of the ion and secondary electron trajectories and the concurrent precursor decomposition indicate that the vertical pillar growth is due to type-1 secondary electrons and primary ions while the lateral growth to type- 2 secondary electrons and scattered ions. The widths of the pillars are comparable to those of EBID pillars.

In general, He-IBID pillars show better characteristics than pillars grown by conventional Ga-focused-ion beams or by electron beams. Moreover, Monte Carlo simulations explain the shape and the growth mode of the nanopillars.

\section{Acknowledgments}

This research is part of NanoNed, a national research program on nanotechnology funded by the Ministry of Economic Affairs in The Netherlands. PDR and DAS acknowledge the support of the Semiconductor Research Corporation (Dan Herr, program manager).

\section{References}

[1] Wagner A, Mauer J L, Blauner P G, Kirch S J and Longo P 1990 J. Vac. Sci. Technol. B 81557

[2] Matsui S, Kaito T, Fujita J, Komuro M and Kanda K 2000 J. Vac. Sci. Technol. B 183181

[3] Gierak J et al 2007 Microelectron. Eng. 84779

[4] Dubner A D, Wagner A, Melngailis J and Thompson C V 1991 J. Appl. Phys. 70665

[5] Ro J S, Thompson C V and Melngailis J 1994 J. Vac. Sci. Technol. B 1273
[6] Okada J S, Mukawa T, Kobayashi R, Ishida M, Ochiai Y, Kaito T, Matsui S and Fujita J 2006 Japan. J. Appl. Phys. 455556

[7] Kometani R, Haruyama Y, Kanda K, Kaito T and Matsui S 2007 Japan. J. Appl. Phys. 467987

[8] Chen P, Salemink H W M and Alkemade P F A 2008 Japan. J. Appl. Phys. 478120

[9] Utke I, Hoffmann P and Melngailis J 2008 J. Vac. Sci. Technol. B 261197

[10] Morgan J, Notte J, Hill R and Ward B 2006 Microsc. Today 1424

[11] Ward W B, Notte J A and Economou N P 2006 J. Vac. Sci. Technol. B 242871

[12] Scipioni L, Stern L A, Notte J, Sijbrandij S and Griffin B 2008 Adv. Mater. Process. 16627

[13] Vladár A E, Postek M T and Ming B 2009 Microsc. Today 176

[14] Hill R, Notte J and Ward B 2008 Phys. Procedia 1135

[15] Bell D C 2009 Microsc. Microanal. 15147

[16] Sidorkin V, van Veldhoven E, van der Drift E, Alkemade P F A, Salemink H W M and Maas D 2009 J. Vac. Sci. Technol. B 27 L18

[17] Winston D et al 2009 J. Vac. Sci. Technol. B 272702

[18] Bell D C, Lemme M C, Stern L A, Williams J R and Marcus C M 2010 Nanotechnology 20455301

[19] Sanford C A, Stern L, Barriss L, Farkas L, DiManna M, Mello R, Maas D J and Alkemade P F A 2009 J. Vac. Sci. Technol. B 272660

[20] Maas D, van Veldhoven E, Chen P, Sidorkin V, Salemink H, van der Drift E and Alkemade P 2010 Proc. SPIE 7638763814

[21] Shuman R, Sundaram G, Lezec H J and Bromley-Barratt J 1999 12th Int. Microprocesses and Nanotechnology Conf.

[22] Smith D A, Joy D and Rack P D 2010 Nanotechnology 21175302

[23] Smith D A, Fowlkes J D and Rack P D 2007 Nanotechnology 18265308

[24] Smith D A, Fowlkes J D and Rack P D 2008 Nanotechnology 19415704

[25] Smith D A, Fowlkes J D and Rack P D 2008 Small 41382

[26] Fowlkes J D, Randolph S J and Rack P D 2005 J. Vac. Sci. Technol. B 232825

[27] Ramachandra R, Griffin B and Joy D 2009 Ultramicroscopy 109748

[28] Friedli V, Santschi C, Michler J, Hoffmann P and Utke I 2007 Appl. Phys. Lett. 90053106

[29] Cawthron E R 1971 Aust. J. Phys. 24859

[30] van Dorp W F, Wnuk J D, Gorham J M, Fairbrother D H, Madey T E and Hagen C W 2009 J. Appl. Phys. 106074903

[31] Thomson J J 1912 Phil. Mag. 24209

[32] Livengood R H, Tan S, Greenzweig Y, Notte J and McVey S 2007 J. Vac. Sci. Technol. B 272547

[33] Carl Zeiss S M T 2010 private communication

[34] Scheur V, Koops H and Tschudi T 1986 Microelectron. Eng. 5423

[35] Alkemade P, Chen P, van Veldhoven E and Maas D 2010 J. Vac. Sci. Technol. B at press

[36] Plank H, Gspan C, Dienstleder M, Kothleitner G and Hofer F 2008 Nanotechnology 19485302

[37] Chen P, Salemink H W M and Alkemade P F A 2009 J. Vac. Sci. Technol. B 272718

[38] Murakami K, Matsubara N, Ichikawa S, Wakya F and Takai 2010 J. Vac. Sci. Technol. B 28 C2C13 